\title{
Editorial: Migration in Asia and the Pacific
}

Éditorial: Migrations en Asie et dans le Pacifique

Editorial: Migraciones en Asia y el Pacífico

\section{Nicola Piper and Yves Charbit}

\section{(2) OpenEdition}

\section{Journals}

Electronic version

URL: https://journals.openedition.org/remi/12439

DOI: $10.4000 /$ remi. 12439

ISSN: $1777-5418$

\section{Publisher}

Université de Poitiers

\section{Printed version}

Date of publication: 1 October 2019

Number of pages: 7-12

ISBN: 979-10-90426-64-1

ISSN: 0765-0752

\section{Electronic reference}

Nicola Piper and Yves Charbit, "Editorial: Migration in Asia and the Pacific", Revue européenne des migrations internationales [Online], vol. 35 - $n^{\circ} 1$ et 2 | 2019, Online since 01 October 2019, connection on 14 April 2022. URL: http://journals.openedition.org/remi/12439 ; DOI: https://doi.org/10.4000/remi. 12439 


\section{Editorial: Migration in Asia and the Pacific Nicola Piper ${ }^{1}$ and Yves Charbit ${ }^{2}$}

This special issue of the European Review of International Migration (REMI) is about migration in Asia and the Pacific. Indeed, it is not feasible, within the limits of a dossier, to provide information on the whole of Asia or to systematically compare the major sub-regions of the Asian continent. Instead, this introduction intends to provide a snapshot that offers some background to this region and to highlight general commonalities and differences.

Throughout its thirty-four years of existence, REMI has published articles on specific countries in Asia: e.g. Japan, Singapore, and China. Previously published special issues were devoted to sub-regions as a whole, such as the Indian subcontinent, or to themes with a regional dimension, such as the practice of Kafala in the Middle East or the Silk Road.

The major fact that makes it impossible to identify characteristics common to the whole of Asia is the extraordinary heterogeneity of this immense continent and the complexities of its migratory movements. The contributions to this issue have one element in common, however, and that is to discuss migration from an intra-regional perspective, i.e. flows within Asia and the Pacific, and thus highlight the existence of intra-regional migration corridors and their respective specificities.

What is true in regard to complex interrelationships in the economic, social, political, cultural, religious and ethnic fields is also true in the field of migration. Indeed, this complexity can be seen diagrammatically in map 1 below.

Several countries, generally the least developed in the region, are typically classified as mainly "migrant senders": Bangladesh, Burma, Cambodia, Indonesia, Laos, Nepal, Pakistan, Philippines and Sri Lanka. Conversely, the most developed ones are usually treated as immigration countries: Japan, Singapore, South Korea and Taiwan. Others, the medium-income countries experience both significant inflows alongside significant outflows: India, China, Malaysia and Thailand. As is well known, with increasing development, emigration countries become primarily migrant-receiving countries (e.g. South Korea) and flows have in fact reversed since the 1950s and 1960s in several countries in Asia.

1 British Academy Global Professor, School of Law, Queen Mary University of London, Graduate Centre, Office No. 606, Mile End Road, London E1 4NS, UK; n.piper@qmul.ac.uk 


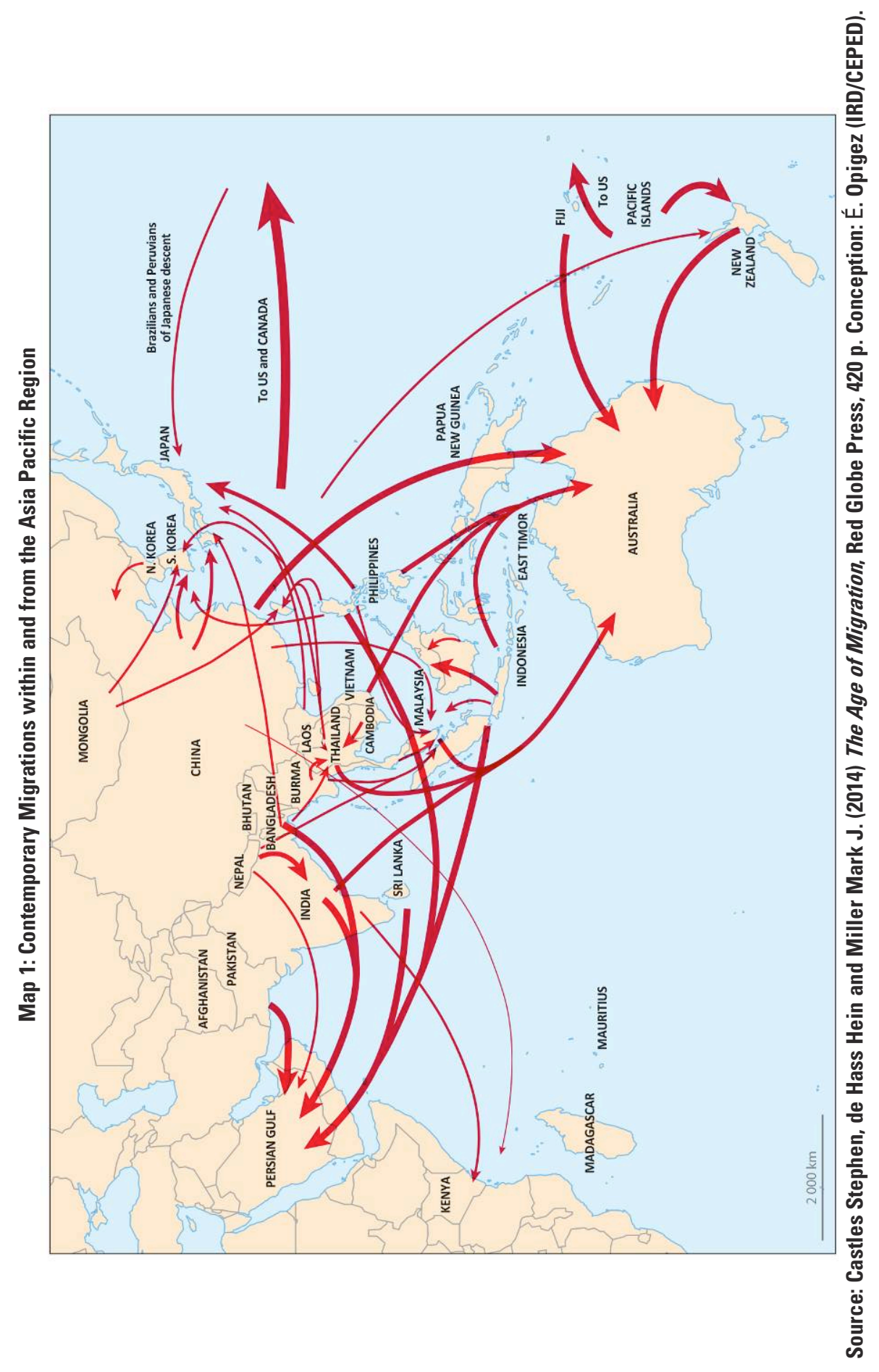


When international student mobility or mobility for skill training as well as the movement of the highly skilled is included, the map of human migration becomes ever more complex with flows going into multiple directions and regional hubs emerging. The global trends towards freedom of movement in (sub-)regional settings has also reached Asia where ease of travel, such as exemptions from visa requirements, is being implemented step by step by ASEAN and has existed for a while between neighbouring countries (IndiaNepal).

Human migration responds to socio-economic opportunities and is thus tied to economic cycles. Certain flows, such as return migration therefore, also occur in the short or medium term, as in the case of the 1997 economic crisis which triggered a return flow of Thai people who had migrated to the United States and other destinations.

In some cases, mobility has deep historical roots, often because of colonial links, particularly in the case of British and Dutch imperialisms, with the recruitment of contract workers (Indenture migration) or sheer forced population movements. Forced migration as an aspect of imperialist projects also played a role in the case of the population displacement triggered by Japan in the 1930s from Korea and China. Politically driven migration resulting in refugee flows is also known to Asia, such as the phenomenon of the "boat people" as a consequence of the Vietnam War. These flows, which have involved millions of people, have led to the formation of diasporas around the world, including in Oceania and parts of Asia particularly in East and South Africa, the United States, Canada and Europe.

Finally, the role of the immigration policies of the countries receiving these flows should not be underestimated in influencing the size and directionality of flows. In addition to North America, both Australia and New Zealand were populated through immigration. The latter countries have traditionally favoured family unification and skilled migration, while others, particularly those in the Gulf region who have lived on oil revenues since the 1970s triggering fast and vast development requiring a large pool of foreign workers due to having been comparatively under-populated and faced with skill shortages, have never had settlement immigration as their objective. As a result of lacking a "melting pot" or "salad bowl" ideology and a free market rein, integration and non-discrimination have never been topics their societies tackled.

Faced with such a diversity of situations, it is to be expected that the characteristics of migrants would also be very diverse. Migration concerns both men and women in their role as primary migrants, but also as those left behind; it concerns low-skilled workers and those recruited for their skills, the so-called "brain drain" or "brain gain"; and those expelled for politico-religious reasons.

At a very general level, and from a strictly statistical point of view, the following table shows that the presence of migrants varies considerably from one sub-region to another, both in absolute numbers and as a percentage of the region's total population. The purely quantitative comparison of Asia with the other major regions of the world, Africa, North America and Europe, is instructive. 
Table 1: Migrants in the Region of the World (stocks and \% of total population)

\begin{tabular}{lcc}
\hline $\begin{array}{l}\text { Major area, region, country } \\
\text { or area of destination }\end{array}$ & $\begin{array}{c}\text { Total stock of migrants } \\
\text { in thousands }\end{array}$ & $\begin{array}{c}\% \text { of } \\
\text { total population }\end{array}$ \\
\hline World & 257,715 & 3.4 \\
\hline Africa & 11,617 & 2.0 \\
\hline Asia & 33,735 & 1.8 \\
Central Asia & 2,831 & 7.7 \\
Eastern Asia & 4,137 & 0.5 \\
Southern Asia & 6,616 & 0.7 \\
South-Eastern Asia & 4,747 & 1.5 \\
Western Asia & 14,314 & 16.0 \\
\hline Europe & 38,822 & 10.5 \\
Northern America & 29,695 & 15.6 \\
Latin America and the Caribbean & 4,670 & 1.5 \\
Oceania & 4,288 & 20.7 \\
Australia/New Zealand & 4145 & 27.8 \\
\hline
\end{tabular}

From the outset, West Asia is a special case. This sub-region includes the oil-producing countries of the Middle East, which rely heavily on foreign labour, mainly from Asia. West Asia has $16 \%$ migrants, ten times more than South-East Asia, for example, and thirty times more than East Asia. On the other hand, it is striking to note that West Asia is the region with New Zealand and Australia, Europe or North America where migrants are most numerous (in \%). Thus, countries whose wealth is based on oil rent and those with a mainly industrial and tertiary economic structure have a common characteristic: the need to use a foreign labour force that is mainly underqualified, but also able to fill skilled jobs.

Of course, Asia is the most populous continent in the world with more than 4 billion inhabitants and nearly 80 million migrants. But this mass effect should not be given too much meaning, since Africa has only 24.6 million migrants, and the proportion of migrants from Africa is slightly higher than that observed in Asia (2 against $1.8 \%)$.

The case of Oceania suggests the same type of observation: Australia and New Zealand alone have 8.1 million migrants, or $96 \%$ of the migrant stock in the region, compared to all twenty-one other micro-States in the region (five in Melanesia, seven in Micronesia and nine in Polynesia).

Despite the fact that migration has been part of human history from its inception, the modern and contemporary era differs from previous historical phases in that it displays ever greater complexity with regard to the nature of the governing arrangements and institutional actors involved in shaping migration. The region in question has also been subject to rising institutionalisation and the multiplication of actors with specific interests in migration. As much as the study of migration has moved beyond structural and economic analyses by shifting migrants' agency to the fore, important contributions have also been made to include the role of non-migrant actors into the analysis of the key factors that mediate and shape migration and migrants' decision making. Supra-national, governmental and non-governmental institutions all play an important role, both 
individually and as part of an institutional web or networks. They typically work in a collaborative manner but at times stand in competition with each other, fillings roles and taking responsibility for aspects of migration left by others or specific groups of migrants (refugees, labour migrants, female migrants, children) that are neglected.

It is therefore not surprising that the theme of governance has repeatedly emerged and is also woven into those contributions to this special issue which point to diverse arrangements and the complexity of geographic, political, institutional aspects of migration governance in the Asia Pacific. As seen elsewhere, migration is regulated in both formal and informal ways. The actions and decisions made by institutions about ways of governing and the design of policies that regulate migration are not necessarily informed by migrants' needs and their experience but shaped by other interests. It is typically civil society organisations, and in particular migrants' ability to self-organise and represent themselves, that bring migrants' voices and lived reality to the attention of decision makers but with varying success. This is particularly vital in regard to the most excluded and vulnerable migrants: the low-skilled, temporary labour migrants - many of whom labour in domestic work, a sector still deemed "informal" - and asylum seekers who have no chances of being formally recognized as refugees in Southeast Asia. The migration laboratory of the Asia Pacific region demonstrates very well the complexities involved in the institutionalisation of migration, the many different interests involved in migration and the diversity of the "migrant" as a category.

The common theme that emerges from the complex picture of the "migration scene" in the Asia Pacific, however, is the central aspect of work, employment and skill development (including study). Securing a livelihood, seeking a better life, social mobility, better education and skill development are all aspirations which centre upon income generation and work. Rural to urban, national to international, gendered, low-skilled, high skilled and refugees: all those migratory flows are tied to the necessity and wish to engage in work and income generation, the acquiring of new skills and further education - for oneself or members of one's family, i.e. the next generation.

What the case of the Asia Pacific demonstrates in this regard is the blurring of market, state and society when it comes to migration governance: deepening economic neoliberalism and socio-political patronage have resulted in a migration governing system characterized not only by diversity and multiplicity of actors but also, and probably are a result of, privatisation and commercialisation of international migration. The lives of migrants and non-migrants (recruiters, families left behind, governmental and non-governmental organisations) in various places (country of origin, destination) are shaped by and contribute to this form of migration governance across space (local, national, regional, global) and place. A complex web of regulatory forces and modes derive from the varying interests and actors. These are the key themes discussed in the contributions to this special issue.

The paper by Asis et al. starts with an overview of academic lenses emerging from the study of intra-Asian migration flows and how those themes and conceptualisations fit into "global" migration research. The historical significance of 
"East meets West" during the colonial period and contemporary global linkages via supply chains capitalism have and are shaping labour migration flows in Asia. The global migration governance frameworks developed by the United Nations impacts on and is impacted upon by regional dynamics and specificities of the Asia Pacific. The UN's key migration agencies (UNHCR, IOM, ILO) with their regional hubs and country offices are discussed by Alice Nah with specific attention being paid to the role of UNCHR in the politically hyper-sensitive area of forced migration. The theme of historical ties is picked up by Lindquist and Xiang in their discussion of recruitment practices and agents in the case of China and Indonesia. As anthropologists, they provide a locally contextualised picture of the role of non-migrant actors in mediating flows across borders.

The contribution by McDonald raises the issue of Australia's shifting identity as "European" on the basis of past immigration waves, to see itself as part of its geographic location: the Asia Pacific. The face of Australian society has visibly become more Asian: from those who originate from all over Asia - East, Southeast, South and West. They make important contributions as entrepreneurs, workers, employers in all sorts of sectors and capacities - and importantly also as students. The final paper by Connell rounds this issue off on the basis of his contribution on the Pacific islands and migration between them as well as to Australia and New Zealand. Despite their geographic size, they display complex flows characterized by multiple directionality and temporality (permanent, short-term).

The legal column in this issue is by Crock, a specialist in immigration law, whose contribution provides an overview of Australia's refugee policy framework. Her analysis of "irregular maritime arrivals" contrasts the comparatively harsh treatment of migrants who arrive by boats (the centre of public debate and international scrutiny) with the country's generous formal admission programs. 